\title{
Bubble sweeping and jet flows during nucleate boiling of subcooled liquids
}

\author{
H. Wang ${ }^{a}$, X.F. Peng ${ }^{a, *}$, B.X. Wang ${ }^{a}$, D.J. Lee ${ }^{b}$ \\ a Department of Thermal Engineering, Tsinghua University, Beijing 100084, China \\ b Department of Chemical Engineering, Taiwan University, Taipei 106, China
}

Received 28 January 2002; received in revised form 16 July 2002

\begin{abstract}
An experimental investigation was conducted to investigate nucleate boiling on a very fine heating wire. By using zoom routine and CCD camera system, the dynamical process of nucleate boiling was visually observed. Sweeping bubbles and several modes of jet flows were described and discussed. For some cases, big bubbles, small bubbles, sweeping bubbles and jet flows coexisted in boiling system, and greatly enhanced heat transfer. These phenomena are quite different from usual observation of nucleate boiling. In this paper, the process of bubble sweeping phenomenon is described in detail and the effect induced by sweeping bubbles is argued. And also, several jet flows are illustrated and discussed, as well as the interaction between bubble sweeping and jet flows.
\end{abstract}

(c) 2002 Elsevier Science Ltd. All rights reserved.

Keywords: Nucleate boiling; Bubble sweeping; Jet flow; Fine wire

\section{Introduction}

Nucleate boiling phenomenon might be one of very well investigated modes among three different boiling regimes [1-3]. However, the detail process of nucleate boiling is quite complicated, and it still remains a great number of unsolved or unclarified problems and phenomena. Boiling nucleation, bubble dynamics, interactions between bubbles, temperature field around bubbles, and the physical nature of boiling regime all need to be investigated more deeply [2]. Various heat transfer mechanisms had been previously proposed to explain the high heat transfer efficiency observed in nucleate boiling, such as macro and microconvection caused by buoyancy, bubble growth and departure, microwedge layer evaporation, and the liquid-vapor mass and heat exchange [4-12]. Marangoni flow and the associated effects which are induced by surface tension gradients along the vapor-liquid interface of bubbles

\footnotetext{
${ }^{*}$ Corresponding author. Tel.: +86-10-6278-9751; fax: +8610-6277-0209.

E-mail address: pxf-dte@mail.tsinghua.edu.cn (X.F. Peng).
}

was noted to be as strong as the previously proposed mechanisms in some special cases, such as in a microgravity environment where natural convection has no effect [13-15]. These investigations have provided a unique way to understand the intrinsic nature of the boiling process.

As traditional nucleate boiling theory, bubbles generate from active nucleate sites on heating surfaces, grow up and depart from heating surfaces due to buoyancy and inertia [3]. The heat transfer associated with liquidvapor phase change is calculated through these normal bubbles.

Frost and Kippenhan [11] indicated that the energy transport caused by the mass exchange at the bubble interface, the evaporation at the bottom and the condensation at the top of the vapor bubble, accounts for most of the boiling heat transfer, especially for subcooled liquid boiling and for convective boiling. The numerical simulations of Christopher et al. [15] showed that the liquid flow around a vapor bubble on the heated surface was mainly driven by the evaporation and condensation at the interface rather than by the Marangoni flow. Existing experimental and theoretical evidences demonstrate that the interfacial heat transfer in a vapor 
bubble and the associated fluid flow dominates the heat transfer, particularly in the low heat flux nucleate boiling mode. However, a thorough understanding of the true nature of the nucleate boiling heat transfer process is still largely lacking.

In this paper, a series of experiments was conducted on a platinum fine wire to observe nucleate boiling phenomenon and associated process behavior. Some emphases are addressed on the discussion of bubble sweeping and jet flow on and from a heating wire.

\section{Experiment device}

The experiment facility mainly consisted of three parts, as shown in Fig. 1. The experimental section contained a heating wire placed in the transparent vessel. The vision acquisition system included a CCD device and computer. The direct current resource supplies power to heat the platinum wire.

The heating wire was a platinum wire with diameter of $0.1 \mathrm{~mm}$ and length of $49 \mathrm{~mm}$, horizontal installed. To keep liquid temperature approximately invariable, the vessel was put in an insulation housing, and a heat dissipate device was employed and installed under the bottom of the vessel.

The direct current power supply was HP Agilent Model-6031A power supply system that can provide the maximum power of $1200 \mathrm{~W}$ and the maximum current of $120 \mathrm{~A}$. In present experiments, the platinum wire was easy to come to burn out for the current higher than $6 \mathrm{~A}$, no matter the work fluid is alcohol or water, saturated or subcooled.

The pressure in the vessel was kept at atmospheric pressure. Direct current passed through the platinum wire and caused its temperature increasing. Finally, boiling happened on the wire surface. By measuring the current and voltage of the platinum wire, the input heat power of the wire was obtained, as well as the resistance of the wire. From the resistance change, the average wire temperature was calculated according to the relation between resistance and temperature of the platinum wire. The bulk liquid temperature was measured by thermocouples placed in the liquid vessel.

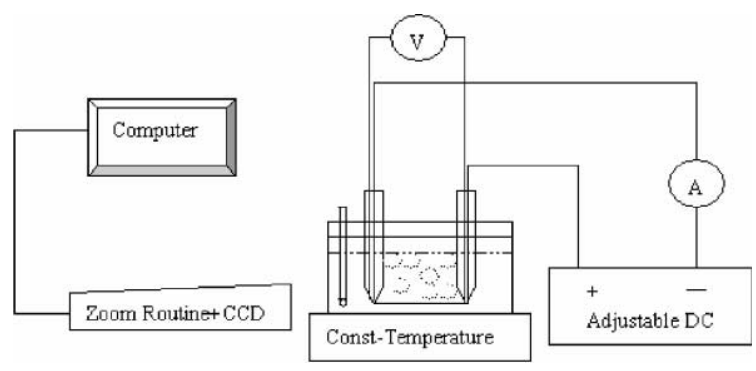

Fig. 1. Experimental system.
Working liquid was very well boiled for several hours before experimental measurement and observation, to get rid of dissolved gases in liquid. This pretreatment also assured the properties of platinum wire to be steady. When experimental run began, working liquid was adjusted to a specified temperature or subcooling, and then DC current was applied through the wire. Vision information was recorded by the acquisition system. In experiments, pure water, 75\% alcohol and 99\% alcohol were used as working liquid, respectively. Three kinds of photo record speed, 125, 250 and 500 frame/s, were selected for obtaining the video image.

\section{Bubble sweeping phenomenon}

\subsection{Forward-and-backward bubble sweeping}

Bubble moving along the surface of heating wall were well known in some boiling experiments, such as forced flow boiling, boiling on a vertical wall [16] and a downward wall [17]. In these cases, some bubbles might sweep along the wall surface instead of detaching from the wall caused by the force of fluid flow or gravity/ buoyancy, and these sweeping bubbles cannot change their moving direction and just move in according with forced flow or buoyancy direction.

In present experiments, sweeping bubbles moved along the horizontal heating wire without forced flow, and they could change moving direction backward when encountering with another bubble. These bubbles came to induce forward and backward sweeping movement along the wire, different from general sweeping bubbles in forced flow, on a vertical wall or downward wall.

A series of photographs is illustrated in Fig. 2 to show the detail process of a bubble sweeping on the heating wire, which was obtained from the boiling of water with a subcooling of $80^{\circ} \mathrm{C}$, and the catching speed of video image used was $250 \mathrm{frame} / \mathrm{s}$.

As shown in Fig. 2a, there are two bubbles attaching on the surface of the wire, referred to bubble I and bubble II, at position of point $\mathrm{A}$ and point $\mathrm{B}$, respectively. At $t=0$, bubble II started to move rightward. In a time period of $0.01 \mathrm{~s}$ and a distance of $0.35 \mathrm{~mm}$, bubble II was accelerated and increased its speed up to $44 \mathrm{~mm} / \mathrm{s}$. After that, bubble II swept rightward across the upper surface of the wire as a constant velocity of $44 \mathrm{~mm} / \mathrm{s}$, approaching to point $\mathrm{C}$ as shown in Fig. $2 \mathrm{~b}$ and $\mathrm{c}$. Then, bubble II experienced a deceleration period of $0.01 \mathrm{~s}$ and came to point $\mathrm{C}$. At this time, bubble II had traveled a distance of $3.59 \mathrm{~mm}$ from point $\mathrm{B}$, and the diameter of bubble II was $0.31 \mathrm{~mm}$. The distance of $3.59 \mathrm{~mm}$ is 11 times of its own size. After a $0.024 \mathrm{~s}$ halt, bubble II restarted to move backward to point B. 


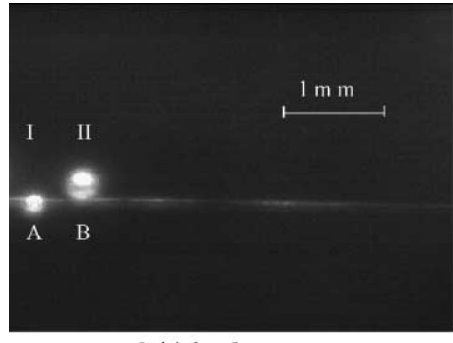

a. Initial $\mathrm{t}=0$

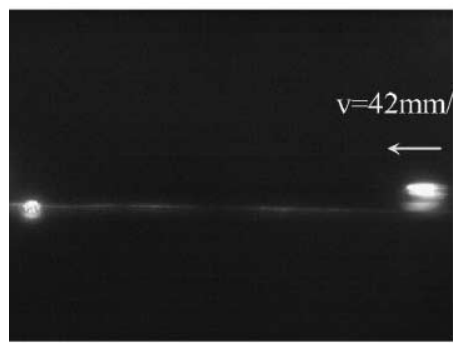

d. $\mathrm{t}=0.172$ s sweep backward

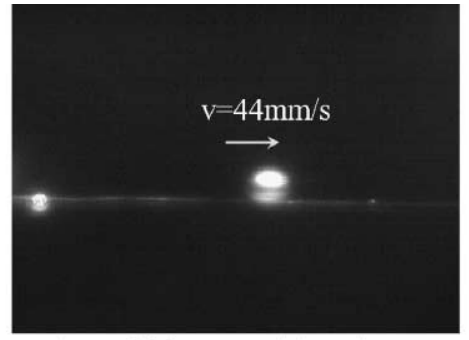

b. $\mathrm{t}=0.044 \mathrm{~s}$ sweep rightward

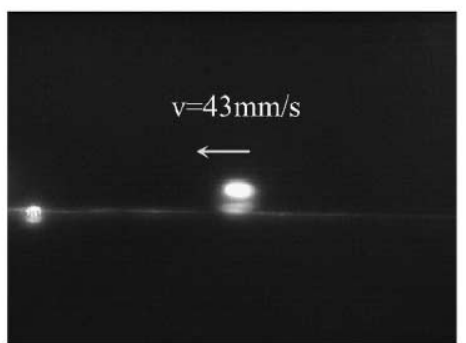

e. $\mathrm{t}=0.212 \mathrm{~s}$

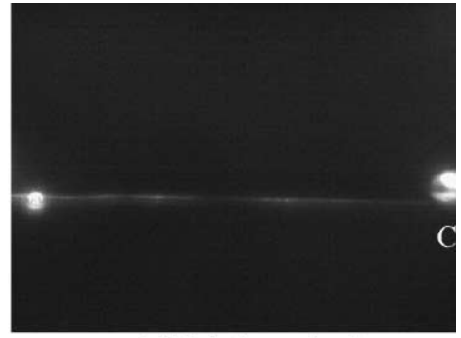

c. $\mathrm{t}=0.120$ s halt at point $\mathrm{C}$

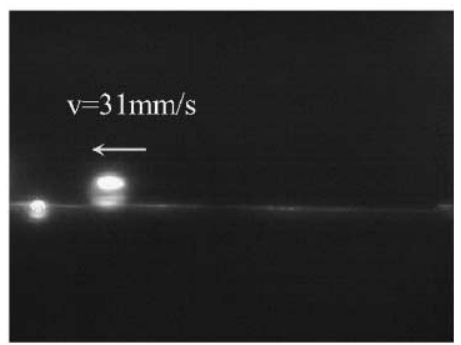

f. $\mathrm{t}=0.244 \mathrm{~s}$ decelerate

Fig. 2. Bubble forward-and-backward sweeping on a heating wire.

As such a circle, bubble II kept sweeping forwardand-backward between point B and C. Some important characteristics are concluded as below.

1. The phenomenon can be observed when bubbles generate separately at active nucleate sites at lower heat fluxes and in the case of subcooled boiling.

2. The experiments indicated that bubble sweeping was not induced by inertial or buoyancy and interaction between bubbles was an important factor. Moving bubbles always halt and reverse when encountering with another bubble with considerable size.

3. Bubble moved very fast, accelerating and decelerating within a very short time and resulted in significant disturbance in vicinity area. In case of Fig. 2, the speed of $40-50 \mathrm{~mm} / \mathrm{s}$ means that bubble II could move 130-161 times of its own size within a second.

\subsection{Induced site interaction}

When one bubble generates and grows at a nucleate site, it may exert influences on other nucleate sites that close to it. Usually, the affecting range of bubble is not beyond three times of its own size [18-20]. However, the forward-and-backward bubble sweeping happens within wide scale and induced long-distance interaction among sites in present experiments. For instance, the observation shown in Fig. 2 indicates bubble II swept within a scale as 11 times large as its own size. The inner interaction mechanism of boiling system is expected to be more complex.

Prompt movement of bubble sweeping generated flow perturbation around the bubble on the wire and induced rapid temperature variation of both the adjacent liquid and the wire, which resulted in the consequence on growth and detachment of bubbles on the wire. A bubble sweeping was able to absorb nucleus/ embryos and restrain their nucleation or supply its vapor into the sites to promote nucleation, as observed by Judd et al. [21]. In Fig. 3, the interaction occurred between two bubbles. They came to collide from far away then breakaway in contrary directions. Sometimes, a sweeping bubble pushed another bubble to move from static state, and perhaps acting on the third and fourth
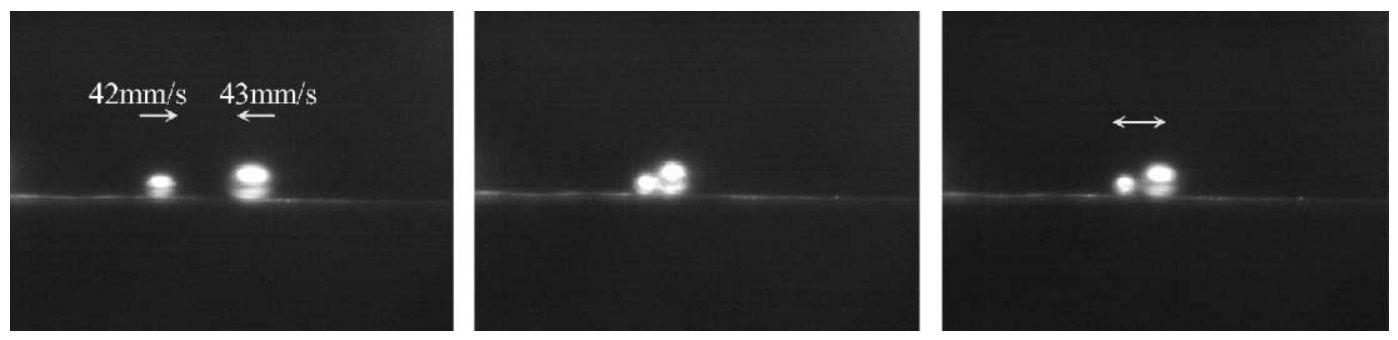

Fig. 3. Bubble collision and detachment. 

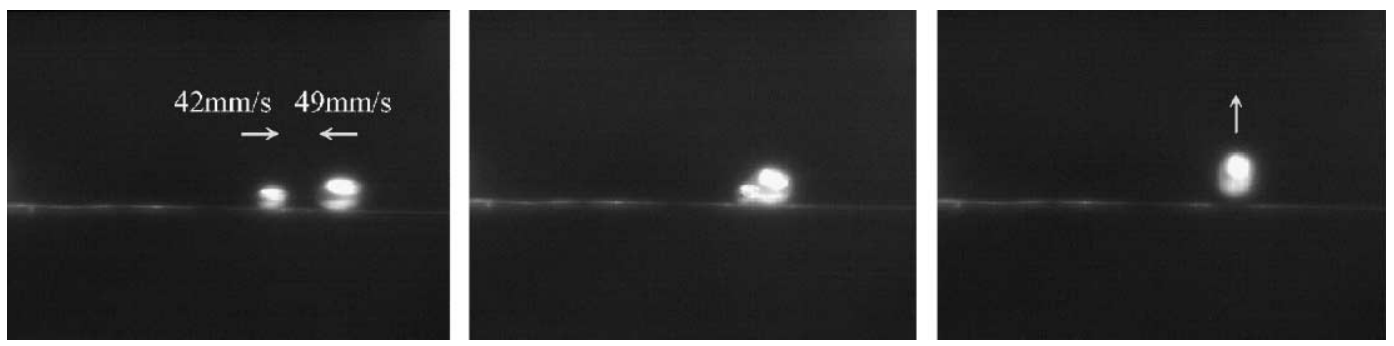

Fig. 4. Bubble collision, coalescence and departure.

bubble, which greatly enlarge interaction range. It was also observed that two neighbored bubbles coalesced into one larger bubble. The process of coalescence and detachment is show in Figs. 4 and $7 \mathrm{a}$ and $\mathrm{b}$.

\subsection{Heat transfer characteristics}

The observed forward-and-backward sweeping can significantly intensify the heat transfer of a single bubble. Evaporation was intensive in microlayer and much heat was absorbed from the wire by this way. As a bubble sweeps across the surface of heating wire, a compared wider microlayer forms and remains on the wire. At the same time, the bottom of bubble keeps contacting high temperature wall in front of it. These apparently enhance the heat removal from the wire, and the heat transfer should be much higher than normal cases [22-25].

On the other hand, for subcooled boiling condensation process happens at the bubble top, as observed by $\mathrm{Li}$ et al. [26]. During sweeping process, the top of bubble always contacts with fresh subcooled liquid, and consequently the condensation process at the top is intensive. Fig. 5 shows boiling of alcohol with subcooling of $57{ }^{\circ} \mathrm{C}$ and wire surface heat flux of about $2.8 \times 10^{5}$ $\mathrm{W} / \mathrm{m}^{2}$. Condensation jets were observed from the top of sweeping bubbles, which are like smog from smokestacks of running locomotives. Working liquid evaporated into vapor from microlayer of bubble bottom, and the vapor condenses as jets at the top of a bubble.

In addition to these, liquid single-phase convective heat transfer is also intensified by sweeping bubbles. In front of movement, bubble pushed the heated liquid near the wire away, while in the wake of flow field made refreshing with subcooled liquid from bulk region.

\section{Jet flows}

Jet flows are quite different from general bubble boiling or sweeping. They generated from nucleate sites on the wire, formed track of tail in bulk liquid. Jet flows are diverse and random, occurring either before common nucleate boiling beginning or during the nucleate

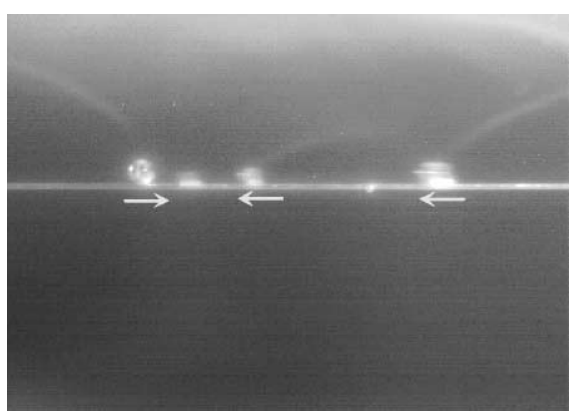

Fig. 5. Condensation jets from sweeping bubbles.

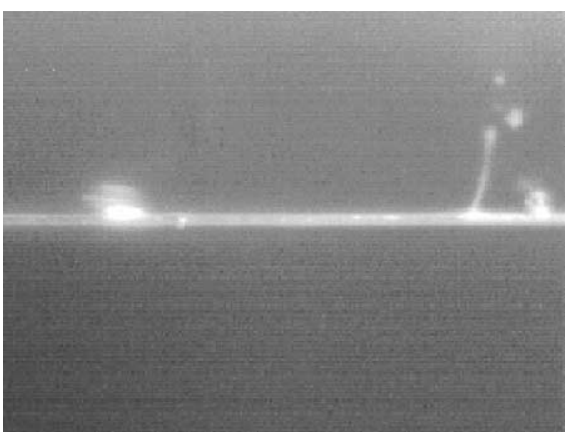

Fig. 6. Close observation of nucleation jets.

boiling process. In earlier experimental observations six different jet flows were reported and discussed, highenergy liquid jet, fog-like jet, cluster-like jet, bubbleforming jet, bubble-bunch jet and bubble-top jet [27].

In present investigation, jet flow and bubble sweeping were observed to coexist for nucleate boiling on a heating wire, as shown in Fig. 5. Fig. 6 illustrates another observation of nucleation jet. It can be seen that there is a fine column connecting the bubble with the wire. This kind of jet ought to consist of pure vapor, which is very different from above mentioned jet flows. More information can be obtained from Fig. $7 \mathrm{~d}-\mathrm{f}$, which shows growth process of nucleation jets.

These jet flow phenomena happened randomly, and so far no body can exactly tell if jet flow will come forth, 


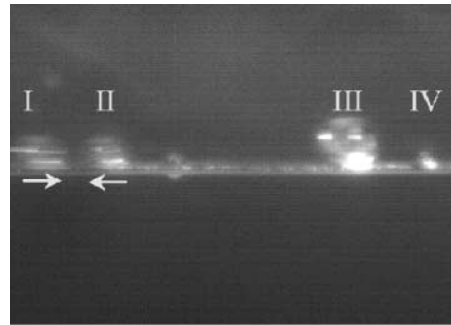

a. $\mathrm{t}=0$, bubble I and II are sweeping

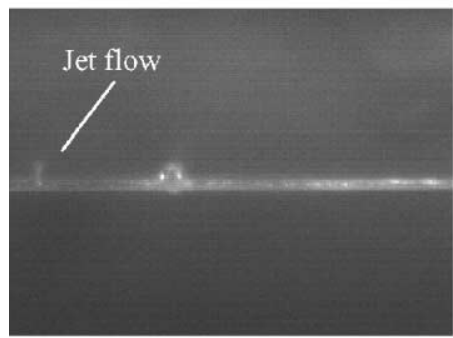

d. $\mathrm{t}=0.12 \mathrm{~s}$

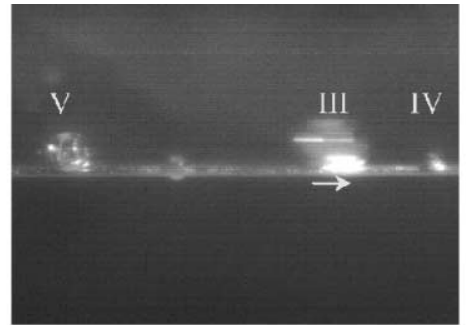

b. $\mathrm{t}=0.016 \mathrm{~s}$, I and II coalesce into $\mathrm{V}$

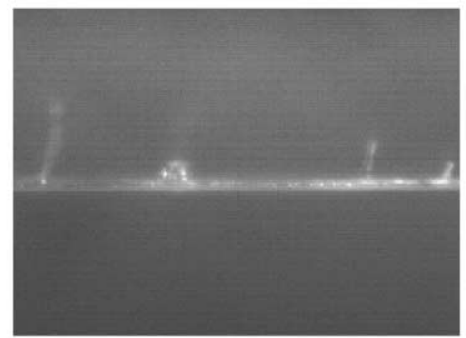

e. $t=0.16 \mathrm{~s}$

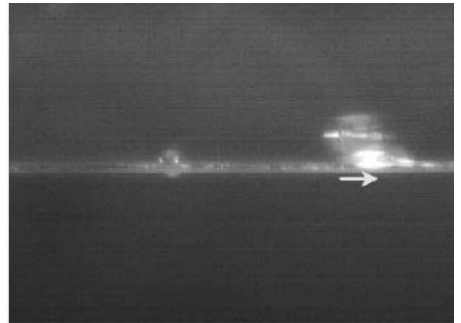

c. $\mathrm{t}=0.08 \mathrm{~s}$, III is devouring IV

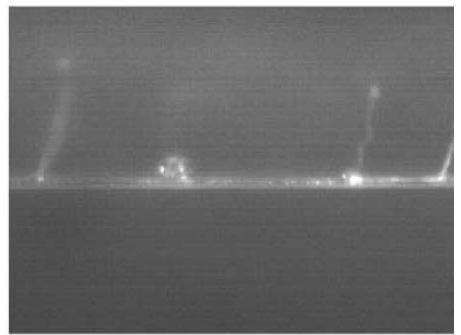

f. $t=0.192 \mathrm{~s}$

Fig. 7. Formation of bubble sweeping and jet flows.

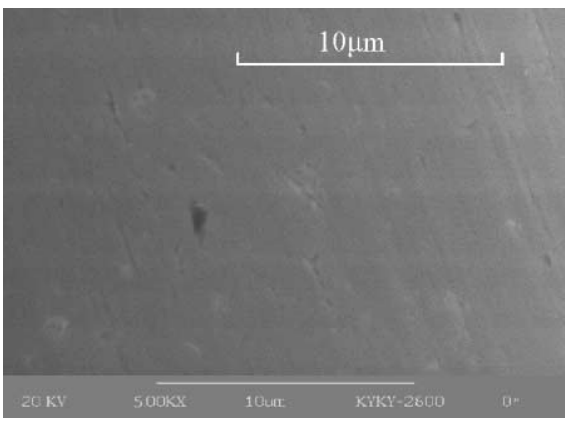

Fig. 8. Surface condition of the heating wire.

or which kind of jets may come forth for specified conditions. The surface condition of heating wall is an important factor in boiling. As an example, a scan photo of the $0.1 \mathrm{~mm}$ platinum heating wire is shown in Fig. 8.

Boiling process is a strong non-equilibrium process. There are bifurcations in strong non-equilibrium and non-linear process. Such rich and colorful jet flow phenomena just indicate these characteristics of boiling.

\section{Diversity of heat transfer mode}

Fig. 7 shows boiling process of liquid alcohol with bulk temperature $32{ }^{\circ} \mathrm{C}$ and heating current $2.48 \mathrm{~A}$. As shown in photos of Fig. 7a-c, bubble sweeping and coalescing phenomena were clearly seen, and from Fig. $7 \mathrm{~d}$ and e, three jet flows generated and grew up. All these happened very quickly, within $0.2 \mathrm{~s}$.
Sweeping bubbles induced significant consequence on the heat transfer performance of the heating wire and they made great heat absorption from the heating wire. When sweeping bubbles and jet flows coexist, jet flows usually played inferior role. Once one bubble started to sweep, it could break and restrain jet flows. More often, jet flows just came forth now and then disappear instantly, and only sweeping bubbles were observed.

The diversity of subcooled boiling can be observed through the photos in Fig. 9. These photos were obtained from the boiling of alcohol with bulk temperature $34{ }^{\circ} \mathrm{C}$ and heating current $3.5 \mathrm{~A}$. There are small bubbles, big bubbles, sweeping bubbles and jet flows coexisting in the boiling system. Small bubbles cannot depart from the wire, but the mass transfer from its bottom to its top also carries considerable heat. Big bubble can devour little bubbles, grow up to some size and depart from the wire. Sweeping bubbles are a kind of big bubbles moving forward-and-backward along the wire. They usually came to coalesce and depart from the wire, at the same time, clean small bubbles in their way, as shown in Fig. 9. Some of jet flows keep jetting at some few sites, some random coming now and then from the sites of the heating wire. Vapor and liquid with high energy is jetted into bulk liquid deeply and much heat is carried out through this way.

Nucleate boiling is a kind of high efficiency heat transfer mode. The fundamental manner of nucleate boiling is bubble generating and departing circle. However, in subcooled liquids, bubbles are difficult to grow up to big size because of condensation at its top, and the 


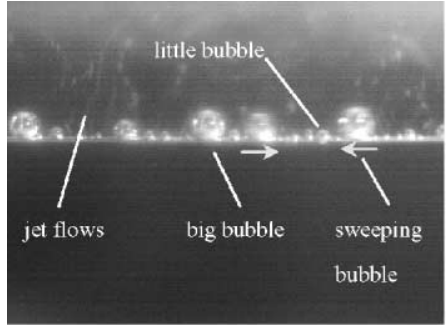

a. $\mathrm{t}=$ (), four factors in boiling system

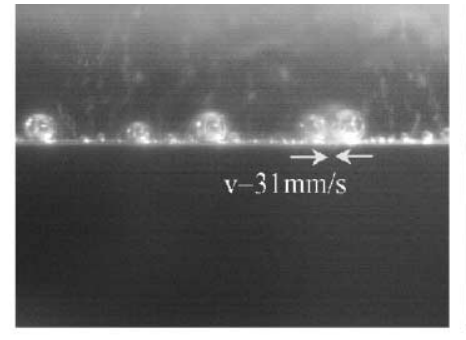

b. $\mathrm{t}=0.032 \mathrm{~s}$, sweeping bubbles

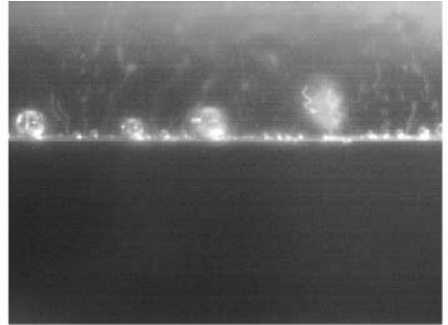

c. $\mathrm{t}=(0.040 \mathrm{~s}$, coalescence and detachment

Fig. 9. Diversity of boiling heat transfer.

thermocapillary flows from their bottom to top exert a counterforce to the bubble and push it attaching on the wire [28]. Both vapor condensation and thermocapillary flow restrain the departure of bubbles, which turns to weaken heat transfer. Jet flows and sweeping bubbles are different from general bubble boiling mode and greatly enhance heat transfer. In all, the diversity of boiling systems always improves the heat transfer performance with a great degree.

\section{Conclusions}

(a) Diversity of nucleate boiling and heat transfer mode was investigated for subcooled liquids on a horizontal heating platinum wire. Jet flows and sweeping bubbles are described and discussed in detail.

(b) Bubble forward-and-backward sweeping phenomenon was experimentally observed along the heating wire. This phenomenon and sweeping bubbles resulted in significant consequence on the liquid flow around bubbles and temperature of liquid and wire, which greatly alters the boiling behavior and heat transfer mode. The bubble interaction was noted to be quite different from normal observation due to bubble sweeping phenomenon.

(c) Jet flows displayed new dynamical behavior while bubble sweeping occurred, and they coexisted in subcooled liquid nucleate boiling. Both jet flow and bubble sweeping greatly enhanced heat transfer.

\section{Acknowledgement}

This research is currently supported by the National Natural Science Foundation of China (contracts no. 59976016).

\section{References}

[1] R.H. Sabersky, Heat transfer in the seventies, Int. J. Heat Mass Transfer 14 (1971) 1927-1979.

[2] V.P. Carey, Liquid Vapor Phase-Transition Phenomena, Hemisphere Publishing House, New York, 1992.
[3] E. Hahne, U. Grigull, Heat Transfer in Boiling, Hemisphere Publishing, New York, 1977, p. 22.

[4] H.K. Forster, N. Zuber, Dynamics of vapor bubble and boiling heat transfer, AIChE J. 1 (1952) 531-535.

[5] D.E. Forster, R. Greif, Heat transfer to a boiling liquidmechanism and correlation, J. Heat Transfer $81 \mathrm{C}$ (1) (1959) 43-53.

[6] C.Y. Han, P. Griffith, The mechanism of heat transfer in nucleate pool boiling - Part I, Int. J. Heat Mass Transfer 8 (1965) 887-904.

[7] C.Y. Han, P. Griffith, The mechanism of heat transfer in nucleate pool boiling - Part II, Int. J. Heat Mass Transfer 8 (1965) 905-914.

[8] F.D. Moore, R.B. Mesler, The measurement of rapid surface temperature fluctuations during nucleate boiling, AIChE J. 7 (1961) 620-624.

[9] S.J.D. van Stralen, The mechanism of nucleate boiling in pure liquid and in binary mixtures-Part I, Int. J. Heat Mass Transfer 9 (1966) 995-1020.

[10] S.J.D. van Stralen, The mechanism of nucleate boiling in pure liquid and in binary mixtures-Part II, Int. J. Heat Mass Transfer 9 (1966) 1021-1046.

[11] W. Frost, C.J. Kippenhan, Bubble growth and heat transfer mechanism in the forced convection boiling of water containing a surface active agent, Int. J. Heat Mass Transfer 10 (1967) 931-949.

[12] V.K. Dhir, Nucleate and transition boiling heat transfer under pool and external flow conditions, Heat Transfer 19901 (1990) 129-155.

[13] J. Straub, The role of surface tension for two-phase heat and mass transfer in the absence of gravity, Exp. Therm. Fluid Sci. 9 (1994) 253-273.

[14] J. Straub, Interfacial heat transfer in microgravity, in: Heat Transfer Science and Technology 1996, Higher Education Press, Beijing, 1996, pp. 11-28.

[15] D.M. Christopher, B.X. Wang, X.F. Peng, Flow field around a condensing and evaporating vapor bubble in microgravity, in: Proceedings of the Molecular and Microscale Heat Transfer in Material Processing and Other Applications, Part 2, 1996, pp. 162-170.

[16] G.E. Thorncroft, J.F. Klausnera, R. Mei, An experimental investigation of bubble growth and detachment in vertical upflow and downflow boiling, Int. J. Heat Mass Transfer 41 (1998) 3857-3871.

[17] K. Cornwell, I.A. Grant, Heat transfer to bubbles under horizontal tube, Int. J. Heat Mass Transfer 41 (1998) 11891197. 
[18] M. Sultan, R.L. Judd, Interaction of the nucleation phenomena at adjacent sites in nucleate boiling, J. Heat Transfer 105 (1983) 3-9.

[19] D.B.R. Kenning, H.M. Victor, Fully-developed nucleate boiling:overlap of areas of influence and interference between bubble sites, Int. J. Heat Mass Transfer 24 (1981) 1025-1032.

[20] C. Andrzej, R.L. Judd, Some aspects of the interaction among nucleation sites during saturated nucleate boiling, Int. J. Heat Mass Transfer 28 (1985) 23312342.

[21] R.L. Judd, R. Mallozzi, N. Balakrishnan, Investigation of randomness, overlap and the interaction of bubbles forming at adjacent nucleation sites in pool boiling, Int. J. Heat Mass Transfer 43 (2000) 3317-3330.

[22] R.C. Hendricks, R.R. Sharp, Initiation of cooling due to bubble growth on a heating surface, NASA TND-2290, April 1964.
[23] R.R. Sharp, The nature of liquid film evaporation during nucleate boiling, NASA TND-1997, October 1964.

[24] N. Hospeti, R.B. Mesler, Deposits formed beneath bubble during nucleate boiling of radioactive calcium sulfate solution, Center for Research in Engineering Science, University of Kansas, September 1964.

[25] R.J. Benjamin, A.R. Balakrishnan, Nucleate pool boiling heat transfer of pure liquids at low to moderate heat fluxes, Int. J. Heat Mass Transfer 39 (1996) 2495-2504.

[26] Z.M. Li, X.F. Peng, D.J. Lee, T. Liu, Mass transfer behavior at bubble surface during nucleate boiling, Heat Mass Transfer 38 (2001) 433-439.

[27] H. Wang, X.F. Peng, B.X. Wang, D.J. Lee, Jet flow phenomena during nucleat boiling, Int. J. Heat Mass Transfer 45 (2002) 1359-1363.

[28] R. Marek, J. Straub, The origin of thermocapillary convection in subcooled nucleate pool boiling, Int. J. Heat Mass Transfer 44 (2001) 619-632. 